\title{
La experiencia del proceso venezolano actual
}

Carmen L. Bohórquez

UNIVERSIDAD DEL. ZULIA, Maracaibo, VenfeZufi.A

La política debe ser el motor fundamental de los cambios en este momento en el mundo. A los que tenemos responsabilidades políticas, deben los pueblos comenzar a exigirnos, porque para algo estamos en estas posiciones, para oir la voz de los pueblos, para actuar en función, no de intereses minoritarios, sino para actuar en función de los intereses de las mayorias, porque sólo asi tiene sustentación ética un mandatario en cualquier parte del mundo. Un jefe de Estado o un jefe de Gobierno que se deje secuestrar por minorias privilegiadas, por más poder que tengan de chantaje o de presión, no merece ser un jefe de Estado, es el jefe de un clan, es el jefe de una secta, no merece ser conductor de un pueblo, y eso es algo que se refleja boy en Venezuela en toda su crudeza. Por primera vez, en muchos años, hay un gobierno aqui que no se ha dejado ni se dejará secuestrar por minorias privilegiadas que se enriquecian al amparo de la inmoralidad de presidentes, de ministros, de gobernadores y de funcionarios de toda calaña. Hoy eso se acabó y lo que está en marcha es un proceso de restitución de la soberania de las mayorias, de restitución del carácter sacrosanto del interés nacional. La voluntad politica debe ser el motor de las transformaciones que el mundo requiere. Particularmente, los latinoamericanos, los africanos y los caribeños debemos incrementar esa voluntad.

Hugo Cháviz. Frias, Fragmento del discurso pronunciado en el III Foro de Alto Nivel sobre la Cooperación entre paises de África, América Latina y el Caribe, Caracas, 19 de febrero de 2002. 
De cuantos trabajos he tenido que escribir en mi vida académica, ninguno tan difícil y complejo de abordar como el presente. Ya no se trata de desarrollar un discurso crítico, develador de códigos opresores en un orden de cosas dado para posibilitar con ello, hipotéticamente, el advenimiento del nuevo orden (que tal cosa tardara un siglo o más en ocurrir, el deber académico y el compromiso intelectual estaban cumplidos), sino ejercer la crítica desde el interior mismo de lo que intenta construirse como ese orden nuevo de justicia y libertad. Es decir, desde el ojo mismo del huracán, desde una práctica vital en la que resulta poco menos que imposible separar la reflexión de la angustia diaria, de la impotencia de no tener más armas que el verbo y de verse confrontada a la brutal comprobación de que se requiere algo más que palabras para construir una nueva realidad y, sobre todo, para enfrentarse en la práctica del día a día con un mundo oscuro de intereses y pasiones que desborda cualquier comprensión bien intencionada.

Se me ha pedido que hable de la experiencia venezolana actual en relación con la teoría y la práctica de la democracia en nuestro contexto sociocultural. Advierto que trataré de hacerlo con la mayor objetividad, pero que no me comprometo a cumplirlo, tan profunda y vital es la experiencia.

Pienso que, en primer lugar, tendremos que analizar qué se está entendiendo por democracia en el contexto venezolano actual, y para ello serán necesarias algunas consideraciones históricas previas.

Como en la mayoría de los países de América Latina, la democracia que se instaura en Venezuela luego de la caída del gobierno del General Marcos Pérez Jiménez, en 1958, se define como representativa, y en tal sentido va a ser fundamentalmente entendida y practicada desde sus aspectos formales: ejercicio del voto, existencia de partidos políticos y un marco constitucional que regula las relaciones entre el Estado y los ciudadanos; más con la finalidad de asegurar la buena marcha del primero que el cumplimiento de los derechos de los segundos. En particular, el hecho de que esta etapa democrática no sólo la va a proveer de una letimidad política incuestionable, sino que, además, le permitirá a los gobiernos de esta nueva etapa presentarse como democráticos en grado sumo, aun cuando en la práctica echen mano de procedimientos que poco se distinguen de los utilizados por la dicta- 
dura. Baste decir que las garantías constitucionales, consagradas en la nueva Constitución democrática que se promulga el 23 de enero de 1961, fueron suspendidas al día siguiente y sólo fueron plenamente restituidas en 1994.

La justificación para tal suspensión fue doble: terminar de limpiar el país de cualquier residuo dictatorial y hacerle frente a una nueva amenaza, tan grande o peor que la superada tiranía: el totalitarismo comunista que desde Cuba amenazaba con tragarse a América Latina y que había provocado en Venezuela la insurgencia guerrillera. Lo que nunca se dijo fue que esa insurgencia guerrillera fue también creada, en cierta manera, por el pacto político acordado en diciembre de 1958 entre los partidos Acción Democrática (socialdemócrata), Copei (demócrata cristiano) y Unión Republicana Democrático, con el propósito, según manifestaron los firmantes del mismo, de garantizar a instauración y permanencia de una democracia plena en Venezuela. Sin embargo, a pesar del propósito, y hasta amparándose en él, dicho pacto excluyó totalmente al Partido Comunista y otras tendencias de izquierda que se habían ganado con honra un lugar en el nuevo orden por su heroica lucha contra la dictadura. Más aún, todos estos grupos fueron declarados ilegales, obligándolos con ello a pasar a la clandestinidad.

La amenaza comunista justificó, entonces, cualquier acción policial o militar contra cualquier sospechoso de simpatizar o de actuar en consonancia con tales ideas y sirvió también, a mi juicio, de elemento distractor que impidió que se profundizara en el debate político y se desarrollara un verdadero ejercicio democrático. Las reglas y los procedimientos formales -en tanto características más visibles y diferenciadoras respecto a un régimen dictatorial - ocuparon el lugar de los elementos sustanciales, y los valores y fines de la democracia quedaron supeditados a los acuerdos políticos de gobernabilidad y de mantenimiento del sistema. Estos objetivos se cumplieron a través del pacto mencionado, conocido como Pacto de Punto Fijo, el cual se mantuvo más o menos vigente hasta las elecciones de diciembre de 1998 , en las que los partidos que lo sustentaban quedaron prácticamente barridos del mapa político. De la misma manera, su expresión legitimante, la ya referida Constitución del 61, sería sustituida por la redactada por la Asamblea Nacional Constituyente y aprobada en referéndum popular el 15 de diciembre de 1999. 
Podemos decir, en todo caso, que el Pacto de Punto Fijo se inscribe en el contexto del proyecto modernizador que ya se había iniciado durante la dictadura, pero que ahora, en las nuevas circunstancias, va a permitir la participación, no sólo de la burguesía tradicional que se adapta rápidamente a las nuevas reglas del juego, sino también de una amplia masa de nuevos burócratas, que muy pronto comenzarán a acumular sus propias fortunas a través del cobro de comisiones o de la autoadjudicación de contratos de servicio o de obras de infraestructura. Otro elemento a destacar dentro del nuevo acuerdo político fue el surgimiento y multiplicación de sindicatos y la regulación de las relaciones obrero-patronales, ambas facilitadas por el control de las organizaciones obreras por parte de Acción Democrática. Por lo demás, y para mayor afirmación de su legitimidad, el pacto logró el respaldo de las Fuerzas Armadas, fue acogido con gran beneplácito por la burguesía local y recibió la bendición de la jerarquía de la Iglesia Católica, la que, dicho sea de paso, verá ampliar sus privilegios y su presencia en la vida política del país, hasta lograrse la firma, en 1964, de una especie de Concordato entre la República y el Vaticano.

En lo económico, hubo igualmente consenso respecto al modelo de desarrollo a seguir y a la distribución de la renta petrolera entre los diversos actores sociales. Básicamente, se siguió el modelo de la CEPAL, con las particularidades que al mismo le imprimía el carácter petrolero de la economía venezolana y que, en cierta manera, se ha mantenido a través del tiempo, incluso durante la dictadura. Las variaciones introducidas en esta nueva etapa tuvieron que ver con la asignación, por parte del Estado, de mayores recursos para la industrialización sustitutiva de importaciones $y$, algo bastante positivo, una mayor inversión social dirigida hacia las grandes mayorías. Vale destacar la masificación de la educación, que permitió la expansión y el fortalecimiento de la clase media.

La consolidación de ese Estado distribuidor de la renta petrolera y mediador de los conflictos sociales favoreció la integración social y política de los diversos sectores productivos y organizó un proceso estable de expresión y satisfacción de demandas que permitió hablar de la existencia de una sólida democracia en Venezuela, al tiempo que se la ponía como ejemplo ante los demás países latinoamericanos '. La alternancia en el poder de Acción Democrática y Copei contribuyó a acentuar esta "buena fama". Tanto así que, incluso el fracaso del mo- 
delo cepalista no alteró para nada el pacto social establecido; simplemente, se buscó reorientar el aparato productivo en función de políticas más modernas, particularmente dentro de las tendencias neoliberales formuladas por los Chicago Boys. Esto demuestra la fuerte imbricación existente en ese momento entre orden político y orden económico-social, órdenes que, en muchos casos, compartían los mismos actores y cuando no lo hacían, se complementaban y legitimaban mutuamente $^{2}$.

Sin embargo, la otra cara de la moneda de esta estabilidad democrática la representa el hecho de que la misma se mantuvo acompañada de una fuerte política represiva contra cualquier demanda social, manifestación de disidencia o reclamo de participación que intentase ir más allá de los canales partidistas aceptados. Y esta represión se ejerció, no sólo durante el período de la insurgencia guerrillera, sino que continuó casi con la misma intensidad después de la "pacificación" de ésta, ocurrida durante el gobierno del socialcristiano Rafael Caldera (19691973). Fueron miles los muertos, desaparecidos y torturados, o los detenidos sin el debido proceso y por tiempo indefinido, a lo largo de la vigencia del Pacto de Punto Fijo. Particularmente afectado resultó el movimiento universitario, la dirigencia obrera de izquierda y los líderes campesinos. Esta "tradición" represiva permite explicar en parte la orden dada por Carlos Andrés Pérez, el 27 de febrero de 1989, de enfrentar el ejército contra un pueblo desarmado que ese día, como dijo alguien, sólo bajó de los cerros a tomar prestado parte de lo que le había sido secularmente negado. De esa masacre, conocida por todos como El Caracazo, aún no se ha dicho toda la verdad.

Retomando el aspecto económico, podemos decir que durante la democracia puntofijista, la lógica del capital se impuso como principio regulador de la sociedad como un todo, "aunque en las condiciones de


de América Latina, y a pesar de las reformas propuestas por CEPAL para corregir las debilidades del modelo desarrollista inicialmente propusto, la marginalidad y el desempleo se hicieron estructurales, lo mismo que la dependencia económica, en tanto que la renta petrolera, a pesar de la nacionalización ocurrida en 1976, no se tradujo en la inversión productiva que el país requería. Por el contrario, el resultado fue un Estado hipertrofiado, financista generoso de viejos y nuevos grupos económicos, prácticamente, sin ningún control de retorno del 
capital y, más bien, dispuesto a olvidar o a condonar las deudas, lo que, a su vez, creó la cultura del despilfarro, del "cuánto bay pa'eso", la entronización entre las clases alta y media del american way of life, etc.; historia harto conocida en nuestro ámbito latinoamericano, que se expresa en una excesiva concentración de la riqueza, por un lado, y en la pauperización proporcional de las grandes mayorías, por el otro.

Como es de suponer, la agudización de las diferencias sociales, el incremento aparejado de la inseguridad personal, la profundización de la crisis de los servicios públicos, unidos a la impunidad de una corrupción, no sólo generalizada, sino hasta "valorizada" como signo de "viveza" criolla, fue minando la legitimidad de la que había venido gozando el pacto. Señales evidentes de ello comienzan a mostrarse en la creciente aparición, fuera de los partidos tradicionales, de grupos de opinión o movimientos sociales que reclaman participación en la toma de decisiones, al menos localmente, así como en la creciente abstención electoral que empieza a manifestarse al inicio de los 80 . Agréguese a eso el problema de la deuda externa, revelado en toda su magnitud en esos mismos años, cuando quedó al descubierto cómo se había hipotecado ad aternum el futuro de nuestra América, con la complacencia y complicidad interna de sus dirigentes políticos.

El Pacto de Punto Fijo estaba, pues, llegando al final de sus días, aun cuando no se lo quisiera reconocer. Los últimos gobiernos anteriores al conflicto político-militar del 92 , intentaron superar la crisis de representatividad, proponiendo un redimensionamiento del pacto social y hasta la formulación de un nuevo modelo socioeconómico que permitiera darle un nuevo rumbo al país. Se crea entonces, durante el gobierno de Jaime Lusinchi (1984-1989), la Comisión Presidencial para la Reforma del Estado (COPRF), con el doble objetivo de hacer más eficientes los aparatos del Estado y darle un nuevo aire a la democracia. Pero todo se quedó en el papel. La falta de voluntad política y la oposición soterrada de los sectores hegemónicos que temían un cambio en las reglas del juego, convirtió a las recomendaciones de la COPRE en un simple saludo a la bandera, lo que provocó, en primera instancia, la renuncia de su primer presidente, Ramón J. Velásquez ${ }^{4}$. La corrupción llegó a niveles realmente vergonzantes a través de RECADI (Régimen de Cambio Diferencial), que hizo de la especulación con el dólar el más grande negociado que imaginarse pueda, dentro de la mayor complicidad e impunidad posibles. 
A pesar del evidente agotamiento del Pacto, los partidos del status quo intentaron, más bien, atornillarlo, pues las alianzas entre cúpulas partidistas y sindicales, que, en realidad, eran una sola cosa, el bien avenido "matrimonio" entre sectores de la burguesía (llamado hoy eufemísticamente "sector privado") y los burócratas y tecnócratas del gobierno, así como entre éstos dos y grupos militares que también se enriquecían apropiándose de tierras de la nación, o con el mercado de la guerra, se nutrían y beneficiaban, precisamente, del mantenimiento de esa situación que, a ojos vista, venía sumiendo irremisiblemente al resto del país en la desmoralización y la miseria.

Este período estuvo, además, caracterizado por la ausencia de propuestas alternativas. El principal partido de oposición (AD O COPEI, según el caso), lo que realmente buscaba era colocarse de nuevo a la cabecera del festín, en tanto que los partidos minoritarios, incluidos algunos de izquierda que en un momento se presentaron como distintos, como lo fue el MAS, buscaban igualmente colocarse en una mejor posición, que también les permitiera meter mano en el reparto. Por lo demás, se respondía a las frecuentes protestas lideradas por grupos estudiantiles o por grupos u organizaciones populares, con los mecanismos de represión habituales.

En conclusión, muy lejos habían quedado los ideales de justicia, libertad e igualdad que habían fundamentado el pacto social del 58 y la Constitución del 61 que lo legitimaba, ideales que sólo vinieron a ser recordados por la clase dirigente cuando la intentona militar del 4 de febrero de 1992, liderada por el Teniente Coronel Hugo Chávez Frías, puso en evidencia la artificialidad de las bases sobre las que se sustentaba ese modelo democrático. Siete años después, el 2 de febrero de 1999, luego de haber estado dos años prisionero por su acto de rebelión, de habérsele sobreseído la causa por la presión popular, de recorrer casi clandestinamente todo el territorio nacional dando a conocer su propuesta de país y organizando un nuevo movimiento político, de haber atravesado la campaña electoral más dura y verbalmente agresiva que se recuerde en Venezuela, y de haber ganado, a pesar de ello, las elecciones con una amplia mayoría sobre el candidato que representaba todo ese pasado puntofijista, ese mismo Teniente Coronel asumió la Presidencia de Venezuela y convocó de inmediato un referéndum para que se decidiera, como en efecto ocurrió, la convocatoria y elección de una Asamblea Nacional Constituyente, que había de redactar

347

La experiencia del proceso venezolono actual 
una nueva Constitución y, por ende, sentar las bases de un nuevo pacto social.

Desde entonces, vivimos en Venezuela un intenso debate político del que es prácticamente imposible sustraerse, lo que indica que no se trata de una reedición de lo ya acostumbrado, ni de un simple reacomodo de las viejas fuerzas, sino que lo que está en juego es la construcción de un nuevo modelo socioeconómico o de una cuarta via, como algunos lo han llamado, de una nueva forma de hacer política y de una redefinición del ejercicio democrático mismo.

\section{La situación actual}

El cambio que se está dando en Venezuela no es otro que el de la aplicación de los principios contenidos en la nueva Constitución, por la que se pretende establecer un modelo de desarrollo sustentable en el que los beneficios sociales, logrados integralmente, estén por encima de los beneficios económicos y en el que la participación ciudadana adquiera un rol protagónico en la toma de decisiones. Un cambio de esta naturaleza no puede ser bien visto por los actores políticos tradicionales, ni comprendido, incluso, por quienes han estructurado su pensamiento de acuerdo a rígidos esquemas ideológicos, sean de derecha o de izquierda. De allí la feroz resistencia de las clases acomodadas, la acerba oposición de la jerarquía católica, la contumaz descalificación de parte de los viejos partidos, el llamado, no tan soterrado, a la sublevación por parte de militares de derecha, la negativa reacción de la ultraizquierda, la posición beligerante de la cámara empresarial, tradicionalmente "neutra" y ahora en estrecha y ahistórica simbiosis con la mayor central de trabajadores, la CTV, todavía controlada por Acción Democrática (su tradicional aliada), desde donde se pretende ahora llevar a cabo un paro que sirva, de acuerdo a sus aspiraciones, de estocada final al proceso de cambios. Last but not least, el inédito rol opositor, ya rayano en la conspiración y vergüenza del verdadero periodismo, de la mayor parte de los medios de comunicación. Rol sobre el cual sería urgente y necesario plantear un serio debate, no sólo relativo a Venezuela, sino al mundo en su conjunto. Baste traer a colación la reciente declaración de un funcionario del gobierno norteamericano sobre la necesidad estratégica de difundir información falsa cada vez que la defensa de sus intereses así lo requiera. 
Retomando el análisis histórico del caso venezolano, vale decir que ninguna de estas posiciones que adversan el proyecto político que representa Hugo Chávez, es nueva. Todas vienen repitiéndose desde la rebelión militar de 1992, sólo que han ido in crescendo, perfeccionándose y sofisticándose en la medida en que se ha ido percibiendo la inevitabilidad de los cambios. Lo que se dice hoy contra Chávez se decía ya en la campaña electoral del 98: que iba a implantar una dictadura o un régimen comunista, que era un fascista, que tenía nexos o era miembro de las FARC, que estaba loco, que era un ignorante y, además, pobre y negro $\mathrm{y}$, por tanto, no estaba capacitado para gobernar. Incluso, lo que hoy aducen como una de las causales para sacarlo del poder, como lo es su supuesto fracaso como gobernante, era ya afirmado como un hecho evidente por el dirigente adeco Antonio Ledezma en 1999, a escasos meses de haber tomado Chávez el poder y cuando todavía se encontraba en pleno debate constituyente. De la misma manera, las encuestas llevan ya mucho tiempo anunciando el descenso vertiginoso de su popularidad y la falta de apoyo popular a su gestión de gobierno; lo que se acentúa particularmente cada vez que se aproxima una elección, se discute una ley crucial o se prepara alguna acción opositora. En este sentido, pocas cosas han cambiado.

Lo que sí es relativamente nuevo y ha agudizado la situación es la concertación de todas esas fuerzas contrarias, anteriormente disgregadas en un solo frente opositor. A pesar de que carecen de líderes de peso (lo que explica que vitoreen a cualquier militar disidente) y de propuestas políticas alternativas (como no sea el regreso al pasado), les une e impulsa una sola idea fija: el derrocamiento de Chávez, sea por la vía de un golpe militar, por la de una intervención foránea —es decir, la que ustedes están pensando--, o sea por la vía del magnicidio. Para provocar cualquiera de las dos primeras, está claro que vienen conspirando desde hace mucho tiempo y desarrollando una estrategia mediática que en mucho nos hace recordar el caso chileno. En esta estrategia, dirigida tanto hacia dentro como hacia fuera del país, han logrado involucrar, además, a organismos internacionales como la SIP, la OIT y la Comisión Interamericana de Derechos Humanos de la OEA, buscando que éstos ayuden a hacer más creíble su versión de lo que acontece en Venezuela y aceleren el desenlace que tanto ansían. Vale decir que en el primero de estos organismos actúa como Vicepresidente el propietario de uno de los diarios que adversa con mayor 
furor a Chávez; en el segundo, siguen siendo miembros principales de su directiva, conocidos dirigentes de Acción Democrática y, en cuanto a la Comisión, ya conocen seguramente su orientación política.

La posibilidad del magnicidio, si bien no ha existido prácticamente en Venezuela, tampoco se puede ignorar. Dadas las correlaciones reales de fuerzas, es evidente que en las condiciones actuales la única manera de detener el proceso es acabando con Chávez, pues por ahora es el único que tiene el ascendiente suficiente como para propulsar la organización popular, y lo está haciendo; el único que puede seguir impulsando y consolidando una redefinición del papel de la Fuerza Armada, transformándola en importante factor del desarrollo nacional y el único que tiene el valor o la terquedad suficiente para resistir las presiones del neoliberalismo.

Actualmente, la estrategia está dirigida a mostrar, por una parte, que en el país reinan la ingobernabilidad y el caos (de allí la intensificación de las marchas, paros, huelgas, etc.), lo que demostraría la incapacidad de Chávez para gobernar y, por la otra, que ya no lo apoyan sus dos pilares fundamentales, es decir, ni el pueblo (de allí las encuestas y las mismas marchas opositoras con gran cobertura mediática), ni los militares (de allí los pronunciamientos sucesivos, magnificados por los medios, de cuatro oficiales hasta este momento).

En pocas palabras, se ha intentado construir, sobre todo en el exterior, una realidad virtual según la cual cualquier atrocidad imaginable resulta pálida ante lo que en verdad se estaría viviendo en Venezuela. Particularmente, el énfasis mayor está puesto en este momento, por lo sensible del tema talvez, en una supuesta ausencia de libertad de expresión o en la amenaza que se cierne sobre ella y sobre la libertad en general, mientras se mantenga Chávez en el poder. Dentro de la simbología que se pretende crear para darle verosimilitud a esta ficción, la oposición ha bautizado como Plaza de la Libertad al lugar donde ahora se reúnen para tocar cacerolas, vestidos de negro, provocando reminiscencias que, dicho sea de paso, no creo que les favorezcan. Igualmente, proliferan las marchas por la libertad, se exhiben pancartas reclamando libertad, se presenta a un militar rebelándose contra el totalitarismo en esa Plaza de la Libertad, etc.; todo con gran cobertura mediática. 
Extrañísima dictadura ésta en la que los canales de televisión privados, que son todos menos uno, que es oficial, se encadenan para transmitir el pronunciamiento de un coronel de la aviación pidiendo la renuncia de Chávez; en la que este mismo coronel, acompañado del mismo grupo que se reúne en la citada plaza, va hasta la residencia oficial a tocar cacerolas y a pretender derribar la puerta principal para sacar de ella a la familia presidencial, sin que el gobierno ejerciera la más mínima acción represiva (se retiraron cuando se cansaron); en la que un periódico puede titular en primera página, en letras rojas de cinco centímetros de altura, un llamado a paro nacional o un pedido de renuncia al presidente con la frase "Todos al paro" o "Que se vaya el loco", sin que ni siquiera se recoja la edición o se le haga una llamada telefónica de reclamo. Y esto sin contar la avalancha de información falsa, de acusaciones infundadas, de manipulación de la información que viene del gobierno o de omisión de la misma, todo con el respaldo que les da lo que yo he comenzado a llamar "la infalibilidad mediática", la cual está resultando hoy más incuestionable que la papal, so pena de que quien la ponga en duda sea "excomulgado" por albergar tendencias totalitarias. En cuanto a los infundios, si se tiene suerte, el agraviado será resarcido a través de la concesión de un derecho a réplica, el cual es normamente ubicado, no en primera página como la acusación, sino en un pequeño recuadro al final izquierdo de alguna página interior. El último de los infundios envolvió incluso a Ignacio Ramonet, quien reaccionó indignado ante lo que calificó de "superchería mediática", reafirmando, de paso, su fe en el proceso venezolano.

La trasposición de los límites de la cordura se ha hecho tan evidente, que esta semana ya han comenzado a aparecer llamados a la reflexión dirigidos a los medios por parte de organizaciones que nada tienen que ver con el gobierno, más bien, que están en desacuerdo con él, pero que advierten el peligro al que conduce el "sobredimensionamiento" y la "artificialidad" de la realidad que vienen construyendo los medios 5 .

Lo que en otros países es impensable, está ocurriendo en Venezuela. Lejos de una ausencia de libertad, yo diría que lo que hay es una sobredosis de democracia, que tal vez. no estábamos preparados para digerirla y de allí los excesos. Muchos quisieran, por miedo, o porque ello favorecería sus planes, que el gobierno se decidiera a ponerle lími- 
te a las manifestaciones de calle, o que le aplicara mano dura a los medios, pero éste considera que tales manifestaciones sólo prueban que se vive realmente en democracia. El conflicto, sin embargo, parece no tener fin.

\section{El combate mediático}

Después de hacerle un seguimiento de varios meses a la información suministrada por la prensa escrita, así como por los noticieros y programas de opinión de la televisión, y de comparar lo afirmado o pronosticado en ellos con lo realmente acontecido, me atrevería a calificar el discurso opositor (en el que incluyo al de los propios medios) como un discurso generado por una especie de wishful thinking, en el que lo deseado toma el lugar de la realidad y determina las acciones a seguir. Se trataría de un discurso que podríamos llamar, si se me permite, antefáctico, en tanto se antepone a los hechos, y en virtud de la fuerza que le da el deseo de que la realidad se adecue a él, genera una serie de acciones que llamaré biperfácticas, en el sentido de que se colocan y desarrollan en un nivel que está por encima de los hechos mismos y que procura substituirlos.

Así, por ejemplo, se lanza la especie de que, dado que el Presidente ha perdido el control de la situación, en cualquier momento emitirá un decreto declarando el estado de excepción. A partir de allí, comienza la oposición a declarar en todos los medios de comunicación posibles, así como sus diputados en la Asamblea Nacional, que es necesario oponerse al estado de excepción, que el mismo tendrá terribles consecuencias sobre la libertad individual $y$, por lo tanto, que es necesario salir a la calle para impedir que tal amenaza se cumpla. Todo ello, sin que ni el Presidente, ni ningún funcionario de gobierno haya mencionado en manera alguna que tal pudiera ser la intención, y a pesar de que la misma Constitución pauta que ni aún en estado de excepción podrán coartarse las libertades públicas. Días después, al no ocurrir nada de lo anunciado, se deja el tema y se toma otro. De ello podría darles numerosísimos ejemplos, tales como la "protección" que el gobierno supuestamente le dio a Montesinos, el apoyo a la guerrilla colombiana, la inminente instauración de un control de cambios, la intervención de los principales bancos, el nombramiento como Ministro de algún personaje de dudosa reputación, los planes para cerrar 
algún periódico o algún canal de 'TV, la oculta intención de reprimir las manifestaciones opositoras (a pesar de que desde que Chávez asumió el poder, no se ha lanzado todavía, por orden suya, la primera bomba lacrimógena), y la última y más extrema de todas: que vivimos en un régimen sin libertades (ergo, una dictadura) y por tanto es necesaria la movilización del "pueblo" y la intervención de los organismos internacionales, preferiblemente, la del gobierno norteamericano, para poner fin a un régimen tan funesto.

Paradójicamente, quienes aparecen como adalides de tales reclamos son los dirigentes de Acción Democrático y de Copei, con Carlos Andrés Pérez a la cabeza, quien, por confesión propia, trabaja las veinticuatro horas del día para derrocar a Chávez. En cuanto al "pueblo" que se moviliza en contra del gobierno, que pide la intervención inmediata de los militares o la renuncia de Chávez, está compuesto, básicamente, además de loa antiguos partidos, por las clases alta y media alta -las que, creo que por primera vez en Venezuela, participan en una manifestación de calle, al igual que los empresarios y ganaderos-, por los directores y estudiantes de colegios o universidades privadas, así como una variedad gama de grupos de extrema derecha y de extrema izquierda. Cuantitativamente, todos ellos representan, a lo sumo, un $20 \%$ de la población; cualitativamente, sin embargo, son los que tienen acceso a los medios de comunicación y los que, en consecuencia, generan matrices de opinión, tanto nacional como internacionalmente.

Esta es, pues, a grosso modo, la situación que se vive actualmente en Venezuela. Cabe, sin embargo, agregar que, por lo que respecta a la interpretación que el público hace de la información que se recibe a través de los medios de comunicación, todo dependerá de cómo uno se ubique ideológicamente frente el proceso. En el caso de adversar los cambios, dirá que lo que recogen los medios es la absoluta verdad y que los días de Chávez están contados (Varias fechas han sido dadas $y$, al no ocurrir lo pronosticado, se va corriendo el Día D en el calendario; la próxima es el 19 de abril). Si, por el contrario, se apoya el proceso de cambios, aunque la campaña mediática haya puesto a algunos a dudar del proceso, cada día es más la gente que pone en cuestión a los propios medios e, incluso, entre los más fanáticos, se ha llegado al extremo, bastante peligroso por cierto, de reclamarle airadamente a estos y hasta a los propios periodistas, el hecho de que oculten o manipulen la verdad (cacerolazos ante El Nacional, agresiones a 
Globovisión, etc.). Lamentablemente, estos reclamos, en lugar de llevar a los medios a hacer un ejercicio de autocrítica, ha acendrado en ellos el espíritu de cuerpo y los ha radicalizado en su posición de antagonismo al gobierno.

\section{Lo que está en juego}

Ahora bien, ¿qué ha provocado esta escisión de la sociedad venezolana y qué es realmente lo que está en juego hasta el punto de movilizar políticamente a todos los estamentos de la misma, cualquiera que sea su nivel económico, grupo etáreo, grado educativo, confesión religiosa o pertenencia étnica? ¿El solo discurso presidencial, encendido y provocador? ¿Un ejercicio avasallante del poder, como algunos aseguran? ¿Una negación real de libertades? ¿La defensa de la democracia? A mi juicio, toda explicación pasa por la respuesta a esta última pregunta y, particularmente, por definir el tipo de democracia que se dice defender, según el caso. Reveladoramente ésta, que sería la discusión que debería ocupar el centro de la diatriba, permanece soterrada, incluso en medios intelectuales. En principio, porque la misma polarización lleva a los individuos a absolutizar sus convicciones y, por tanto, a creer que acceder a una discusión sobre cuestiones fundamentales podría significar un debilitamiento de su posición.

Si bien es cierto que hoy nadie se atreve a poner en duda la afirmación general de que la democracia constituye la mejor forma de gobierno, en tanto que, teóricamente, hace posible el cumplimiento de los derechos fundamentales de libertad, justicia e igualdad entre los hombres, resulta igualmente evidente que estas nociones están igualmente sometidas a condicionantes históricos que instrumentalizan su sentido en función de una determinada concepción acerca de los modos de relación humana o en función de determinados intereses de poder.

Esta claro, por ejemplo, que desde la totalización economicista que pretende imponer el neoliberalismo sobre los modos de organización de la vida material y espiritual de los diversos pueblos y culturas, estos valores esenciales de la democracia han dejado de ser considerados como fines en sí mismos, para convertirse en condiciones de posibilidad de una sociedad mundial de consumo. Es la lógica del mercado la que determina la viabilidad de los programas de desarrollo humano, 
los planes de salud o educativos, las reformas legales, los proyectos de industrialización, la protección del ambiente y hasta el fomento de la cultura.

Desde esta concepción, fundamentalista por lo demás, se ha lanzado una ofensiva de "resignificación" de términos, valores, principios, necesidades y acciones que reduce al individuo, en el ejercicio de su subjetividad, a ser productor de bienes de consumo o consumidor de estos mismos bienes, y todo lo que atente contra ello es considerado, por decir lo menos, anacrónico, trasnochado e inhibidor de libertades (entiéndase, de competencia, de ganancia, de circulación de capitales).

En este proceso de vaciamiento de la condición humana, no sólo se intenta resignificar la noción de democracia, sino también la de una serie de conceptos históricamente asociados a ella, tales como nación, Estado, ciudadanía, soberanía, voluntad popular, e incluso las propias nociones fundamentales de libertad, igualdad y justicia. De la misma manera, al pretender desdibujar las fronteras del Estado-Nación e imponer al mercado como espacio privilegiado de las relaciones entre los hombres, pierden sentido las nociones de solidaridad, bien común, consenso, y en su lugar se fomentan las de crecimiento, competencia y ganancia. De la misma manera, la búsqueda del bien común es entendida como la búsqueda de la maximización de los beneficios privados, en el supuesto de que estos, a la larga, crearán las condiciones para que la sociedad en su conjunto eleve su bienestar. En el camino habrán de perderse algunas vidas humanas que, en todo caso, como en cualquier análisis contable, representan el costo inevitable de la meta perseguida.

Bajo esta concepción, el Estado debe abandonar toda función protectora o interventora que pueda coartar la realización plena del mercado. En caso de no hacerlo, a buen seguro que sus políticas públicas habrán de ser consideradas "indefinidas", "inadecuadas", "anacrónicas", "de orientación poco clara", etc., lo que terminará por endosarle, al que así actúa, la temida calificación de "país de alto riesgo", con las que las calificadoras de riesgo, garantes de la nueva ortodoxia, van dirigiendo el aterrizaje de los capitales por las distintas regiones del planeta, con el propósito de asegurarles a estos las máximas ganancias y de mantener atemorizados a los diversos Estados a fin de que, un tanto acorralados, se vean obligados a desmontar su empalizada. 
De la misma manera, al consagrarse la extraterritorialidad del capital y ver disminuido el Estado su poder normativo y contralor, la relación capital-trabajo resulta igualmente alterada y nociones como la lucha de clases, derechos laborales, redistribución de las riquezas, reforma agraria, adquieren un tinte no sólo dèmodé, sino "peligrosamente" comunistoide, al que habría que condenar y combatir radicalmente antes de que, irremisiblemente, provoque un caos económico del cual la nación no pueda recuperarse. Es evidente que con esta condena se pretende sacar del ámbito de la discusión pública la profundización acelerada de la desigualdad social que la aplicación del modelo neoliberal trae aparejada como condición de su propia realización.

Podemos, entonces, decir que si la idea moderna de la democracia había separado lo político de lo social, esta idea postmoderna la pretende reducir prácticamente al solo ámbito económico. Bajo esta visión, todo queda mediatizado por la maximización de las ganancias, incluida la verdad o la libertad, hasta el punto de que resulta válido promover o amparar sus contrarios en tanto favorezcan la obtención de beneficios monetarios o la primacía de determinados intereses ${ }^{6}$.

Ante esta nueva forma de hegemonía que ha despojado a la democracia de su sentido de espacio de realización humana, para reemplazarlo por el de espacio de realización plena del mercado, se hace hoy necesario, si es que no queremos terminar de perder los últimos vestigios de autonomía que nos puedan quedar, adelantar una fuerte defensa del Estado-Nación y de su función, tanto como mediador entre capital y trabajo, que como posibilitador de un compromiso entre ambos, que preserve la justicia y la dignidad humanas. Para ello, se hace imperativo recuperar el lugar de la política en la sociedad y convertirla, como dice Hugo Chávez, en "el motor fundamental que el mundo requiere... particularmente, los latinoamericanos, los africanos y los caribeños debemos incrementar esa voluntad".

Estas reflexiones vienen a colación porque, a nuestro juicio, la arremetida contra Chávez no es ajena a la entronización del neoliberalismo como forma única de relación humana, y esto lo podemos comprobar en los argumentos mayormente utilizados en su contra. Particularmente, se combate acerbamente su tesis de que si queremos recuperar la dimensión de lo ético en la sociedad, es necesario reivindicar la intervención de la política sobre la economía, lo cual es considerado pecado capital por los adalides del nuevo evangelio económico. 
Evidentemente, una reivindicación del papel de la política en la sociedad implica necesariamente una "reingeniería" del concepto de democracia que pueda devolverle a ésta su sentido dignificador de la persona humana, garante de la vida antes que garante de los derechos de los propietarios o de los consumidores, y que sobreponga el cumplimiento real de los derechos fundametnales de libertad, igualdad y justicia por sobre los procedimientos formales, que es lo que se quiere significar cuando se define al Estado como un Estado de Justicia.

\section{Un nuevo modelo democrático}

A este respecto, el proyecto de país contenido en la nueva Constitución de la República Bolivariana de Venezuela va más allá de la tradicional noción de democracia representativa, al desarrollar la noción de democracia participativa y protagónica. Se pretende con ello que la democracia no se reduzca a la sola aplicación de normas procedimentales, o al mero ejercicio de la soberanía popular a través del voto, sino que implique la diaria construcción colectiva de más y mejores condiciones de realización humana.

Como expresión máxima de esta concepción de democracia y del intento de hacer realidad un nuevo pacto social, la Carta Magna aprobada en referéndum popular el 15 de diciembre de 1999, defiende a la nación venezolana como un "Estado democrático y social de Derecho y de Justicia", en el que la solidaridad y la corresponsabilidad constituyen principios que guían la acción individual, transformando la participación del ciudadano en los asuntos públicos en una acción ética que lo compromete con el colectivo.

Lamentablemente, o talvez expresamente, la álgida polémica planteada hoy en Venezuela y proyectada al exterior, ha impedido que se conozca y discuta lo que hay de verdaderamente esencial en este proceso que se ha iniciado en nuestro país: la propuesta contenida en la nueva Constitución de un modelo democrático que, al radicalizar la condición de ciudadano a través de su participación en prácticamente todos los niveles de decisión, refuerza el sentido de pertenencia a un conglomerado nacional, fortalece el concepto de Estado-Nación y reafirma el concepto de soberanía, lo que, sin duda, contradice las tendencias globalizantes. 
A grandes rasgos, la Constitución de la República Bolivariana de Venezuela está dirigida, como ya señalamos, a transformar el Estado venezolano en un Estado democrático y social de Derecho y de Justicia, creando un nuevo ordenamiento jurídico que permita el funcionamiento efectivo de una democracia social y participativa en la que se garanticen las condiciones para un desarrollo humano autónomo y digno, y en donde el poder se ejerza desde el cumplimiento cabal de los derechos humanos. Al reforzar la centralidad de los derechos humanos, todo acto del poder público que viole o menoscabe los derechos garantizados por la Constitución y la ley, resultan nulos per se y los funcionarios que los ejecutaron, responsables sin excusa alguna.

Al especificar que la democracia no sólo debe ser representativa, sino además participativa y protagónica, se busca expresamente que no sólo el Estado sea democrático, sino que también lo sea la sociedad, esto es, que todos los elementos que la integran estén signados por los principios democráticos. Esta participación se expresa a diferentes niveles. Por lo que respecta al Estado mismo, se propone un régimen federal regido por los principios de integridad territorial, cooperación, solidaridad, concurrencia y corresponsabilidad, en el que las comunidades y autoridades de los distintos niveles político-territoriales participen en la formulación de las políticas públicas comunes a la nación. A nivel práctico, se estipula un Consejo Federal de Gobierno integrado por el Vicepresidente o Vicepresidenta, los Ministros, los Gobernadores de todos los estados, un representante de los Alcaldes por cada estado y representantes de la sociedad organizada, quienes tendrán como atribución la planificación y coordinación de políticas y acciones para el desarrollo del proceso de descentralización y transferencia de competencias del Poder Nacional a los Estados y $\mathrm{Mu}-$ nicipios. Este Consejo ha de administrar el Fondo de Compensación Interterritorial, destinado al financiamiento de inversiones públicas dirigidas a promover el desarrollo equilibrado de las regiones, así como obras y servicios esenciales para las comunidades, y cuyo monto será determinado cada año por el mismo Consejo. Un Consejo similar se establece a nivel de los Estados y Municipios, igualmente con participación de la sociedad organizada, incluidos los representantes indígenas allí donde estén presentes.

Esta democratización del poder se extiende, incluso, más allá de la esfera pública: sindicatos, gremios, federaciones, partidos políticos, etc., 
están obligados a elegir directa, universal y públicamente sus directivos o autoridades, a través de un proceso electoral que debe ser validado por el Consejo Nacional Electoral. Vale decir que anteriormente estas directivas eran escogidas a través de elecciones de segundo y tercer grado, en las que los acuerdos políticos privaban sobre la voluntad del electorado?.

Por lo que toca a los ciudadanos, se consagra el derecho a la participación en todos los asuntos públicos, sea de manera directa, semidirecta o indirecta; participación que no sólo implica el sufragio, sino también la intervención ciudadana de manera permanente en el proceso de formulación, ejecución y control de la gestión pública. Con ello se busca superar los déficits de gobernabilidad que han afectado tradicionalmente el sistema político, debido a la separación entre Estado y sociedad. En este sentido, concebir la gestión pública como un proceso en el cual se establece una comunicación fluida entre gobernantes y pueblo, implica modificar la orientación de las relaciones entre el Estado y la sociedad para devolverle a esta última su legítimo protagonismo. En la práctica, esta participación le permite al ciudadano postularse a cargos por iniciativa propia (art. 67); revocar los mandatos dados: Todos los cargos son revocables (art. 71); proponer leyes (art. 204); aprobar o rechazar en referéndum decretos presidenciales, enmiendas o reformas constitucionales, o decisiones de trascendencia nacional como puede serlo la integración al ALCA (art. 341); integrar los Comités de Evaluación de los postulados a cargos del Poder Judicial (Tribunal Supremo de Justicia y Jueces de la República), del Poder Electoral, así como a Fiscal General, Contralor General y Contralores Estatales y Defensor del Pueblo (art. 296).

De la misma manera, la nueva Constitución le otorga a las comunidades el derecho de control de la gestión pública integrando los Consejos de Planificación y Coordinación de Políticas Públicas, tanto en el ámbito de los estados, como de los municipios y parroquias (arts. 166 y 182). En estos consejos, cuando sea el caso, estarán igualmente representadas las comunidades indígenas.

Asimismo, se estipula la transferencia de servicios en materia de salud, educación, vivienda, deporte, cultura, programas sociales, etc., a las comunidades organizadas; al igual que el derecho a decidir, formular y administrar directamente sus propios proyectos de inversión (art. $184 \mathrm{I}$ ), bien a través de cooperativas, empresas comunales, o cuales- 
quiera otra forma de organización. Para tales efectos, se ha estipulado que el $20 \% \mathrm{dl}$ fondo corresponde al desarrollo económico de los estados sea manejado directamente por las comunidades organizadas, con lo cual se reafirma la soberanía del pueblo y la autonomía de lo local.

Por lo que respecta a los derechos de los pueblos indígenas, creemos que esta Constitución representa uno de los modelos más avanzados en esta materia. Y vale decir que los derechos en ella incorporados no son una concesión de la sociedad blanca a las minorías étnicas, sino una exigencia de las propias comunidades indígenas, las cuales formularon y presentaron el respectivo proyecto ante la ANC (Arts. 119-126). Es así como quedó consagrado el reconocimiento de sus modos de "organización social, política y económica, sus culturas, usos y costumbres, idiomas y religiones, así como su hábitat y derechos originarios sobre las tierras que ancestral y tradicionalmente ocupan y que son necesarias para desarrollar y garantizar sus formas de vida".

Asimismo, se reconoce su medicina tradicional, sus prácticas económicas y su derecho a participar en la economía nacional y a definir sus prioridades. Se garantiza y protege la propiedad intelectual colectiva de los conocimientos, tecnologías e innovaciones de los pueblos indígenas, prohibiéndose el registro de patentes sobre estos recursos y conocimientos ancestrales. Más aún, se garantiza su derecho a la participación política nacional, asegurándose en consecuencia "la representación indígena en la Asamblea Nacional y en los cuerpos deliberantes de las entidades federales y locales con población indígena" . Además de estos artículos y del reconocimiento oficial de sus lenguas, en el capítulo referente al Poder Judicial, se reconoce plenamente el derecho de los pueblos indígenas a aplicar, dentro de sus comunidades, sus propios códigos de justicia (art. 260).

En cuanto a derechos humanos en general, los mismos quedan garantizados conforme al principio de progresividad y sin discriminación alguna (art. 19); adquieren jerarquía constitucional (art. 23), el Estado se obliga a sancionar y reparar su violación (arts. 29 y 30); los delitos por esta causa son imprescriptibles y se prohibe la desaparición forzada de personas (art. 45) y la tortura (art. 46), incluso bajo estados de excepción. Muy ligado a estos artículos está el que determina que los militares que incurran en la violación de algunos de estos derechos serán procesados y sancionados por los tribunales ordinarios (art. 261). Como vemos, la centralidad de los derechos humanos en

\section{0}

Realidad 87, 2002 
esta Constitución es indiscutible y sustenta la definición del Estado como un Estado de Justicia".

Por otra parte, en este texto se reafirma el alcance de la democracia, no sólo en el ámbito interno, sino también externo. Es decir, se declara como principio constitucional el respeto a la soberanía y autodeterminación de todos los pueblos del mundo y se concibe la relación entre estos, como libres y simétricas con total respeto de las decisiones de cada cual, principio que el Presidente Chávez aplica al pie de la letra y que le ha traído no pocos roces con los Estados Unidos.

Resumiendo lo anterior, no nos cabe duda de que la nueva Constitución de la República Bolivariana de Venezuela sienta las bases para la construcción de una democracia que procedimental y sustantivamente tenga como criterio central la vida de la gente, sin exclusiones de ninguna especie y en condiciones de dignidad y equidad para todos los sujetos; posibilidad tanto más cierta en cuanto se sustenta sobre un real ejercicio de la soberanía popular a través de mecanismos de participación directa en la toma de decisiones y en el control de la gestión pública. Hacer efectiva esta participación no es, por supuesto, tarea fácil, ni es de esperar que lo sea en un plazo perentorio. Está por delante una gran tarea educativa, sin la cual resultaría talvez imposible introyectar los valores que deben sustentar e impulsar dicha participación, entre ellos, la elevación de la autoestima personal y colectiva; la recuperación crítica de la memoria histórica que posibilite el compromiso con un proyecto común; el fortalecimiento del sentido de pertenencia a una comunidad y a una nación, lo que ha de traducirse en la noción de corresponsabilidad en la construcción del nuevo orden.

De la misma manera, es imperativo extender los beneficios de la educación a toda la población, pues la soberanía política y económica sólo puede sustentarse sobre la soberanía cognitiva, para usar la terminología de Edgar Morin. De allí que uno de los compromisos manifiestos del gobierno es el fortalecimiento y democratización de la educación. A tales efectos, se ha priorizado la inversión educativa por encima de cualquier otra inversión, pasando ésta del 3\% del PTB en los gobiernos anteriores, al $7.4 \%$ en el presente año ${ }^{10}$, siendo la meta en corto plazo llevarla al $10 \%$ que pauta la UNESCO. 
El eje central del nuevo proyecto educativo nacional es, siguiendo las enseñanzas del gran maestro Don Simón Rodríguez, formar ciudadanos que hagan de la República una entidad verdaderamente autónoma, libre y soberana. Esto quiere decir que la acción educativa debe estar dirigida al rescate del sujeto como constructor de su propio destino, éticamente responsable de sus decisiones y acciones, y solidariamente consciente de su pertenencia a una comunidad y a una nación. Sobre estos supuestos se ha sometido a consideración de la Asamblea Nacional un Proyecto de Ley de Educación, producto de meses de trabajo en asambleas educativas a lo largo y ancho del país. Por supuesto, también la Asamblea considera otros proyectos presentados por sectores ligados a la educación privada, los que, evidentemente, persiguen otros objetivos.

Entretanto, el gobierno ejecuta el Programa de las Escuelas Bolivarianas, que restituye, a nivel de las escuelas básicas, el concepto de formación integral y del doble turno escolar. Este programa va acompañado de un programa alimentario y, vale decir, que con todo y las deficiencias que aún presenta, es sorprendente la mejora del rendimiento académico y el nivel casi nulo de deserción escolar. Igualmente se realiza una cuantiosa inversión en educación técnica y agrícola, y para apoyar y fomentar la producción de conocimientos de alto nivel, se creó el Ministerio de Ciencia y Tecnología. Este ministerio, en el esfuerzo de democratizar la educación, ha desarrollado además un exitoso programa de computación (Infocentros) a lo largo y ancho del país, incluidas las zonas indígenas.

Contra la realización de los objetivos y metas propuestas conspiran, evidentemente, las precarias condiciones en que se desenvuelve la vida material de nuestros pueblos, particularmente, en un contexto globalizante como el actual, lo que hace aún más ingente la tarea de asegurar la posibilidad misma de vivir para todos y cada uno de los sujetos, condición sine qua non del ejercicio real de sus derechos ciudadanos. Razón más que fundamental -y así lo recoge la Constitución- para fortalecer la presencia del Estado en la actividad económica (art. 112), no sólo como ente promotor, sino también como contralor de dicha actividad (arts. 229,320). Por otra parte, sólo un Estado fortalecido puede desarrollar programas sociales a gran escala que permitan paliar las condiciones extremas de miseria en las que vive la gran mayoría de los habitantes de esta nuestra América, asegu- 
rándoles atención médica básica, educación gratuita y extendida a toda la población en edad escolar y la posibilidad concreta de acceder a viviendas dignas y a los productos de la dieta básica; ninguna de las cuales sería posible bajo un Estado neoliberal.

Como bien lo señala Enrique Dussel, antes que la participación ciudadana o la búsqueda del consenso, está el aseguramiento de las condiciones materiales de existencia. Es la vida, y no otra cosa, la condición de posibilidad de todos los derechos y, por tanto, de la democracia, por lo que no puede hablarse legítimamente de democracia cuando se posterga para el largo plazo, tal como pretenden los defensores del mercado, la atención a los más demunidos, a los excluidos. Recortar o eliminar los programas sociales es una acción éticamente condenable. Si el nivel de sobrevivencia se estima en la cantidad de dos dólares diarios, el recorte equivalente de los gastos sociales en el presupuesto de un país equivale al recorte diario de una vida humana.

A este respecto, el programa de gobierno del Presidente Chávez no sólo concede un peso fundamental a la inversión social, sino que coloca la atención a los más desvalidos como una acción perentoria. En consonancia con esta necesidad, se ha puesto en marcha en Venezuela, desde 1999, un plan de atención masiva de la población, denominado Plan Bolívar, el cual bien podría considerarse la acción humanitaria de mayor alcance jamás realizada en América Latina. Este plan, dirigido a proporcionar atención médica a todos los niveles, a reparar o construir escuelas, dispensarios, hospitales o centros comunales, carreteras o vías de penetración agrícola, muros de contención, tanques de almacenamiento de agua, a realizar mercados solidarios, proporcionar orientación legal o sicológica, o atender cualquier otra necesidad planteada por las comunidades más pobres, es gerenciado por la fuerza armada y ejecutado con la participación de los militares, de profesionales de diversas disciplinas y por las propias comunidades, con el apoyo de diversos organismos públicos y privados. El Plan Bolívar se desarrolla por todo el país, en jornadas intensivas durante los fines de semana, utilizando un poco esa ancestral forma de organización del trabajo que en Venezuela se llama "cayapa".

Por otra parte, este programa fortalece la integración cívico-militar y permite que la Fuerza Armada cumpla con el mandato constitucional de incorporarse activamente al desarrollo nacional. Aunque cuenta con un gran respaldo por parte de los sectores populares, es fuerte- 
mente atacado por la oposición y por un grupo de militares - la mayoría, en retiro-, que se dicen institucionalistas y que considera que estos sólo deben salir de sus cuarteles para defender la soberanía o restituir el orden interno, cuando el mismo resulta alterado. Personalmente, cuando oigo esto, no puedo dejar de pensar en el Caracazo. En todo caso, nos sumamos a la idea de que en las actuales condiciones políticas y militares del mundo, se impone una transformación del rol de los militares, particularmente, en países como los nuestros que no representan una amenaza para nadie, ni tenemos intenciones - ni nunca las hemos tenido- de andar invadiendo a nadie. Amén de que se trata de profesionales altamente capacitados que bien pueden contribuir a la superación de la problemática social".

A pesar de la apretada síntesis que hemos traído aquí, no creo que resulte muy difícil imaginar cuál podría ser el resultado en términos de radicalidad democrática y de establecimiento de condiciones dignas de reproducción de la vida humana y de la naturaleza, si el proyecto contenido en la nueva Constitución llegara a concretarse plenamente; amén del "temible" ejemplo que pudiera representar este modelo para otros pueblos en las mismas condiciones.

No quiere esto decir que no se hayan cometido errores: se han cometido, y muchos. También se han dado casos graves de corrupción y se seguirán dando, pues ya se trata casi de un rasgo cultural que tomará mucho tiempo erradicar. Aún falta mucho por andar y los obstáculos se multiplican día a día, pero no hay otra opción que enfrentarlos y tratar de profundizar en los cambios. Por ello, es explicable que la oposición haya arreciado sus ataques y comprendido la necesidad de organizarse y hacer un frente unido a pesar de sus insalvables diferencias. Esto comenzó a ocurrir a partir del mes de noviembre pasado, cuando se promulgaron y empezaron a aplicarse un conjunto de leyes que ponen en práctica los principios constitucionales, entre ellas, la Ley de Tierras y Desarrollo Agrario, que pretende hacer justicia en el campo acabando con el latifundio, dotando de tierras a los campesinos que no las tienen, ordenando el territorio y garantizando la seguridad alimentaria mediante un mejor aprovechamiento de los suelos y el estímulo a la productividad. La promulgación de esta ley fue la que, básicamente, lanzó a la calle a los terratenientes y a los empresarios asociados a la actividad agrícola a realizar marchas de protesta por primera vez en su vida. Me permito agregar que, con- 
trario a lo que se pretende hacer ver, no está planteado en ningún momento en esta ley la violación del derecho de propiedad, ni expropiaciones irracionales.

La pregunta que nos toca ahora responder, vistas las divergencias entre el modelo de democracia que define la nueva Constitución y el modelo que defienden los distintos sectores que conforman la oposición, es de si existe en estos momentos una posibilidad real de superar la conflictividad existente y lograr consenso en torno a un proyecto común de país. Personalmente, no lo creo posible por el momento, pues no se trata en este caso de disputas entre partidos con ideologías similares o complementarias enfrentándose por cuotas del país, sino del enfrentamiento de dos visiones antagónicas de sociedad y de país, antagonismo que abarca desde la propia noción de democracia, el papel del Estado en el desarrollo económico del país, la orientación de ese desarrollo, la preponderancia de la participación popular, el carácter social de la propiedad que la Constitución consagra y que la burguesía rechaza, la autonomía de los pueblos indígenas, las relaciones de cooperación entre el sector civil y el militar, la manera de ejercer la soberanía, y hasta los nuevos ritos y símbolos de poder que se han tejido a partir de la propia personalidad de Chávez.

La misma oposición está consciente de que Chávez no puede dar ni dará marcha atrás en su proyecto para acoger los planteamientos que ésta le hace; lo contrario sería traicionar sus promesas electorales y su propia historia, con lo cual sí perdería totalmente el apoyo popular. De la misma manera, ya la oposición ha comprobado fehacientemente que Chávez no es ni presionable, ni chantajeable, ni corruptible. De allí que las protestas no estén dirigidas a modificaciones puntuales de ésta o aquella ley, sino hacia un único y obsesionante motivo: Sacar a Chávez del poder. Tal intención puede verse materialmente expresa en las pancartas que se exhiben en las manifestaciones de calle, cualquiera que haya sido el motivo de la convocatoria. Paralelamente, se trabajan, además, otras vías: desde pretender forzar la Constitución para adelantar un referéndum revocatorio (el cual no sería posible sino hasta finales de 2003), o su destitución por parte de la Asamblea Nacional -aunque no tienen mayoría para hacerlo-, un golpe militar, una intervención directa de los Estados Unidos y hasta el magnicidio. 
Este enfrentamiento, magnificado, abonado y, hasta en muchos casos, originado por los propios medios de comunicación, radicaliza cada vez más las posiciones y está creando un clima de tensión entre la población, sumamente peligroso. Se juega al caos y al miedo, buscando una intervención de los militares de derecha o la inhibición del apoyo popular al proceso. El leitmotiv actual es que hay una crisis de gobernabilidad peor que la que existía cuando se decidió destituir a Carlos Andrés Pérez y, por tanto, hay que proceder de la misma manera. La veracidad de la crisis de gobernabilidad no sólo es negada rotundamente por el gobierno, sino que organizaciones no gubernamentales como Provea, que no simpatiza precisamente con Chávez, ha manifestado públicamente su preocupación por el hecho de que "se esté incitando la ilegalidad, lo que implicaría el desconocimiento de la voluntad popular, porque el Presidente, gústele o no a la oposición, fue elegido democráticamente" en 1998 y electo en 2000. La misma organización precisa que la oposición difunde la imagen de que "el gobierno es una dictadura y se representa a sí misma como la única posibilidad democrática y a sus acciones, como la expresión de la "sociedad civil", mientras a los partidarios del gobierno, como propias de "turbas"”. Evidentemente, concluye, se está creando una "crisis social artificial" que impide, por supuesto, el diálogo entre gobierno y oposición $^{12}$.

El diálogo se hace igualmente imposible en tanto se estén hablando dos lenguajes diferentes. Mientras que, desde una democracia participativa y protagónica, las protestas, marchas y otro tipo de reclamos ante los diversos organismos e instituciones, son interpretadas como el ejercicio pleno de un derecho constitucional y por ello deben ser respetadas, la oposición, en cambio, las presenta como signo de ingobernabilidad. Mientras el gobierno considera un avance el que la Constitución consagre a Venezuela como un Estado de Justicia, el presidente de FEDECÁMARAS considera que nada puede estar por encima del Estado de Derecho y que con el agregado de Justicia se da pie a que se viole el derecho de propiedad y otros derechos económicos. Mientras el gobierno considera que el medio más eficaz para erradicar la pobreza y el desempleo es democratizando, tanto la educación como la economía, esto es, elevando cuantitativa y cualitativamente el nivel escolar de la población y apoyando la creación y fortalecimiento de la pequeña y la mediana industria a través de créditos a tasas de interés

\section{6}


preferenciales, y hasta sin interés alguno para los más pobres ${ }^{13}$, la oposición considera que "la superación de la pobreza no se limita a un problema distributivo de la riqueza... [sino que] pasa por el empleo, y éste, por la empresa productora formal". En otras palabras, que los préstamos del gobierno deben estar dirigidos, como en el pasado, hacia las empresas ya establecidas, que son las que tienen la experiencia y una mayor capacidad productiva y las que, por tanto, a la larga podrán resolver el problema del empleo.

Podríamos seguir hablando durante horas, pero creo que lo dicho puede darles una idea general de lo que efectivamente está ocurriendo hoy en Venezuela. Tenemos en desarrollo un movimiento nacionalista, ciertamente, pero en el sentido de que el país ejerza su autonomía y haga respetar su soberanía; que cree firmemente en la integración latinoamericana, hasta el punto de que constituye un mandato constitucional; que se define ideológicamente como bolivariano; que reivindica el concepto de Estado-nación y que pretende no estar subordinado sino a los intereses de las grandes mayorías. Evidentemente, parece estar marchando contracorriente en tanto se aparta de las tesis neoliberales, tan elogiadas por muchos. De hecho, este intento de resistirse a los cantos de las sirenas globalizantes es visto por algunos como un sueño anacrónico o como una quijotada, en tanto que otros, lamentablemente con poder en el mundo, lo ven como un peligro que debe ser observado con atención, no vaya a ser que, como decía la Corona española de Miranda, "se convierta en la chispa que incendie la pradera”. Esperemos que Venezuela no corra la misma suerte que el Precursor.

¿Cómo podrá, entonces, dirimirse el conflicto? Aparte de una salida militar de derecha, la decisión está en las manos del pueblo, en la consolidación de la organización y de la participación popular que, aunque poco se refleja en la pensa, se viene conformando desde hace tiempo y tomando iniciativas cada vez con mayor autonomía. Se requiere también mayor compromiso de parte de sectores de la clase media y de intelectuales de izquierda, los que todavía opinan aisladamente, y se requiere también solidaridad internacional que refuerce el piso político ante los Estados Unidos. De todos modos, lo que ya nadie podrá evitar, aun en el caso de que el proceso fuera interrumpido, es que la ciudadanía deje de participar en la resolución de sus problemas. Me atrevería, incluso, a decir que el grado de participación

\section{7}

La experiencio del proceso venezolano actual 
política de hoy día es, quizás, sólo comparable al alcanzado durante el período independentista. Nadie permanece indiferente. Y ya por esto vale la pena seguir defendiendo este proceso.

Termino con una frase de Isaías Rodríguez, actual Fiscal General de la República:

Las clases altas, las clases medias, las clases académicamente formadas tienen ideas formadas, $y$ esas ideas son sus verdades. Y se piensa que el pueblo no es capaz de cambiar esas verdades, porque no está instruido o porque es ignorante. Sin embargo, el pueblo tiene la fuerza del movimiento, que es lo que cambia las verdades.

\section{NOTAS}

1. Cfr. Gómez, L., López, M. y Maingón, T., Del Pacto de Punto Fijo al pacto social. Fondo Editorial Acta Científica Venezolana, Caracas, 1989.

2. Heinz Sontag y Thaís Maingón, Venezuela: 4-F 1992. Un análisis sociopolítico. Editorial Nueva Sociedad, Caracas, 1992, p. 82.

3. Ibid., pág. 83.

4. En parte por esta renuncia, "debida a la falta de voluntad política para emprender reformas en serio", y también por su nivel intelectual y trayectoria reconocida, Ramón J. Velásquez fue escogido por el Congreso Nacional para asumir el resto del mandato presidencial de Carlos Andrés Pérez, luego de su destitución y enjuiciamiento en 1993.

5. Una de las advertencias viene de Prove:A, una ONG reconocida por su seriedad en la defensa de los derechos humanos, y la otra de Datanál.ISIS, una de las principales encuestadoras del país, a la que tampoco se la puede acusar de estar congraciada con el gobierno.

6. “...hoy en día al sistema no le sirve de nada la verdad. Considera que la verdad y la mentira no son criterios pertinentes en temas de información. Actúa de manera totalmente indiferente ante la verdad o la mentira... La información se ha converrido, ante todo, en una mercancía. Ya no tiene una función cívica". Ignacio Ramonet, "El periodismo del nuevo siglo", en La Factoria, n 8, febrero de 1999 , pp. 5-6 (www.lafactoriaweb.com).

7. En meses recientes se celebró por primera vez en Venezucla un proceso de elección directa de las directivas de sindicatos y confederaciones de trabajadores. Quien se proclama ganador de la confederación más importante del país, la CTV, se niega a enviar las actas de escrutinio correspondientes al Consejo nacional Electoral. De hecho, la mitad de estas actas se encuentran aún extraviadas. Sin embargo, tanto la prensa nacional como la cámara de empresarios han obviado este "detalle" de las actas extraviadas y de la negativa a cumplir con lo pautado 
por la Constitución y han reconocido a Carlos Ortega, dirigente de Acción Democrática y con largos años en el control del gremio de los trabajadores, como representante "legítimo" de estos. Más recientemente, se dio a conocer una grabación en la que Ortega recibe instrucciones de Carlos Andrés Pérez sobre la necesidad de intensilicar la conflictividad laboral hasta llegar a una huelga general indefinida que presione la salida de Chávez del poder. Esta huelga está pautada para el lunes 18 de marzo.

8. Más aún, una representante indígena acaba de ser elegida Segunda Vicepresidenta de la Asamblea Nacional, cuestión impensable hace tres años.

9. Recientemente, en declaraciones dadas a los medios de comunicación, el Presidente de Fedecámaras, Pedro Carmona Estanga, reclamó indignado que el Estado de Justicia tuviera que privar sobre el Estado de Derecho, ya que con ello se ponía en peligro el derecho de propiedad y otros derechos económicos. Estas declaraciones las hizo a raíz de una sentencia del Tribunal Supremo de Justicia, en la que se declaran usurarios los créditos indexados (también llamados mexicanos) y obliga a los bancos a recalcular esos préstamos y a devolver a los deudores el dinero cobrado en exceso, lo que asciende a billones de bolivares.

10. Desde que comenzó a aplicarse la nueva política educativa, se han incorporado al sistema escolar un millón seiscientos mil niños, ha disminuido considerablemente la deserción escolar y se ha incrementado el rendimiento académico.

11. También en Perú y, más recientemente, en Argentina, sus respectivos presidentes han manifestado la intención de que los militares se vinculen más a la sociedad civil desarrollando programas de este tipo. Incluso en los Estados Unidos, la Primera Dama anunció el año pasado que se enviarían militares a todas las escuelas para dar clases de ética.

12. "PRON'FA. La ONG advierte sobre "incitación a la ilegalidad". "Crisis social artificial" impide el diálogo". Diario Panorama, mićrcoles 6 de marzo de 2002. Cucrpo 2, p. 10.

13. Al efecto, se han creado el Banco del Pueblo y el Banco de la Mujer, que conceden microcréditos a personas o grupos de personas que deseen emprender alguna actividad productiva. Como se trata de personas de bajos recursos, estos bancos no exigen las garantías que sí establece la banca comercial. 